\title{
Genetic heterogeneity and HOMOG analysis in British malignant hyperthermia families
}

R Robinson, J L Curran, W J Hall, P J Halsall, P M Hopkins, A F Markham, A D Stewart, S P West, F R Ellis

\begin{abstract}
Malignant hyperthermia (MH) is an autosomal dominant genetic condition that presents in susceptible people undergoing general anaesthesia. The clinical disorder is a major cause of anaesthetic morbidity and mortality. The UK Malignant Hyperthermia Group has performed genetic linkage analysis on 20 large, well defined malignant hyperthermia families, using hypervariable markers on chromosome 19q13.1, including the candidate MH gene RYR1, the gene coding for the skeletal muscle ryanodine receptor protein. The results were analysed using LINKAGE to perform two point and multipoint lod scores, then HOMOG to calculate levels of heterogeneity. The results clearly showed genetic heterogeneity between MH families; nine of the families gave results entirely consistent with linkage to the region around RYR1 while the same region was clearly excluded in three families. In the remaining eight MHS families there were single recombinant events between RYR1 and MH susceptibility. HOMOG analysis was of little added benefit in determining the likelihood of linkage to RYR1 in these families. This confirmation of the presence of heterogeneity in the UK MH population, along with the possibility of the presence of two MH genes in some pedigrees, indicates that it would be premature and potentially dangerous to offer diagnosis of MH by DNA based methods at this time.

( $¥$ Med Genet 1998;35:196-201)
\end{abstract}

Keywords: malignant hyperthermia; genetic heterogeneity; HOMOG

Susceptibility to malignant hyperthermia (MHS) is inherited as an autosomal dominant trait. ${ }^{1}$ The condition manifests itself in otherwise healthy, susceptible people only during general anaesthesia and is triggered by the commonly used inhalational anaesthetic agents (for example, halothane, enflurane, isoflurane), as well as by depolarising neuromuscular blocking drugs (suxamethonium). Although prompt recognition and appropriate treatment have markedly reduced the mortality rate in recent years, malignant hyperthermia remains an important factor in anaesthetically induced morbidity and mortality.

Two reports published in 1990 suggested linkage of the malignant hyperthermia locus to chromosome 19q13.1-q13.2. ${ }^{23}$ McCarthy et $a l^{\beta}$ examined three Irish families using several 19q markers and reported a high probability of linkage to chromosome 19. Other reports of linkage to the same region were published by Stewart et $a l^{4}{ }^{4}$ Ball et $a l,{ }^{5}$ and Couch et al. ${ }^{6} \mathrm{~A}$ proposed candidate gene in this region is the gene coding for the skeletal muscle sarcoplasmic reticulum calcium release channel (CRC), alternatively known as the ryanodine receptor gene (RYR1). ${ }^{2}$ This suggestion was supported by reports that a particular mutation had been found in the homologous gene to RYR1 in pigs that suffer from a similar, but perhaps not identical, disorder. ${ }^{78} \mathrm{~A}$ later paper suggested that chromosome 19 studies have advanced to the point where diagnosis of susceptibility to $\mathrm{MH}$ by linked marker analysis is possible in a large family that has been intensively investigated. ${ }^{9}$ This view has not been widely accepted because of several reports of exclusion by linkage analysis of the RYR1 locus in other $\mathrm{MH}$ pedigrees. ${ }^{10-12}$

In this paper we present the results of the largest series of $\mathrm{MH}$ families investigated for linkage with markers for RYR1 and flanking regions of chromosome 19q13.1-13.2. The likelihood and extent of genetic heterogeneity were formally assessed using the HOMOG computer program. ${ }^{13}$

\section{Patients, materials, and methods}

Patients came from 20 large, well characterised families known to the Leeds Malignant Hyperthermia Unit. All patients and their relatives were tested by in vitro contracture testing (IVCT) in accordance with the protocol of the European Malignant Hyperthermia Group. ${ }^{14}$ Details of the results of their contracture tests are available on request from the corresponding author. The pedigrees of the families are shown in fig 1. Ethical committee approval was granted for this study by the Leeds Healthcare/St James's University Hospital NHS Trust Clinical Research (Ethics) Committee.

DNA was extracted from blood samples and subjected to analysis using primers flanking hypervariable microsatellite repeats ${ }^{15}$ in the RYR1 gene ${ }^{16}$ and the flanking markers D19S47, ${ }^{15}$ D19S191, ${ }^{17}$ and WUT1.9 (W Wolz, personal communication). The sequences of the primers are available on GDB. ${ }^{18}$ These were then end labelled with $\gamma^{33} \mathrm{P}$ ATP using T4 polynucleotide kinase (Northumbria Biologicals Ltd) and subjected to amplification by the polymerase chain reaction (PCR) ${ }^{19}$ under the following conditions. There was an initial 10 minutes denaturation at $94^{\circ} \mathrm{C}$; there followed 


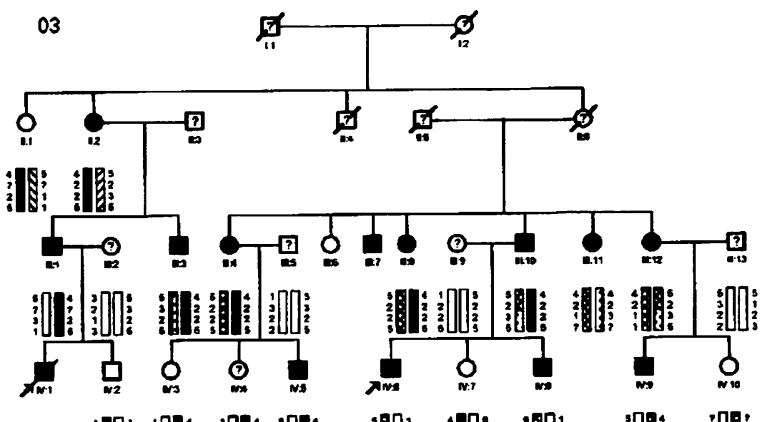

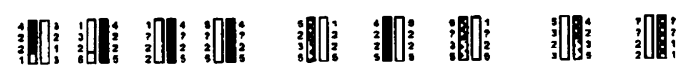

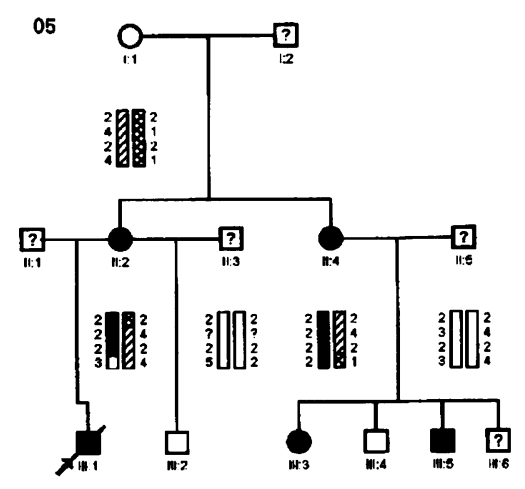

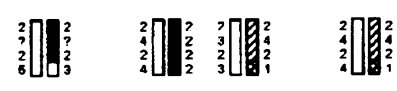
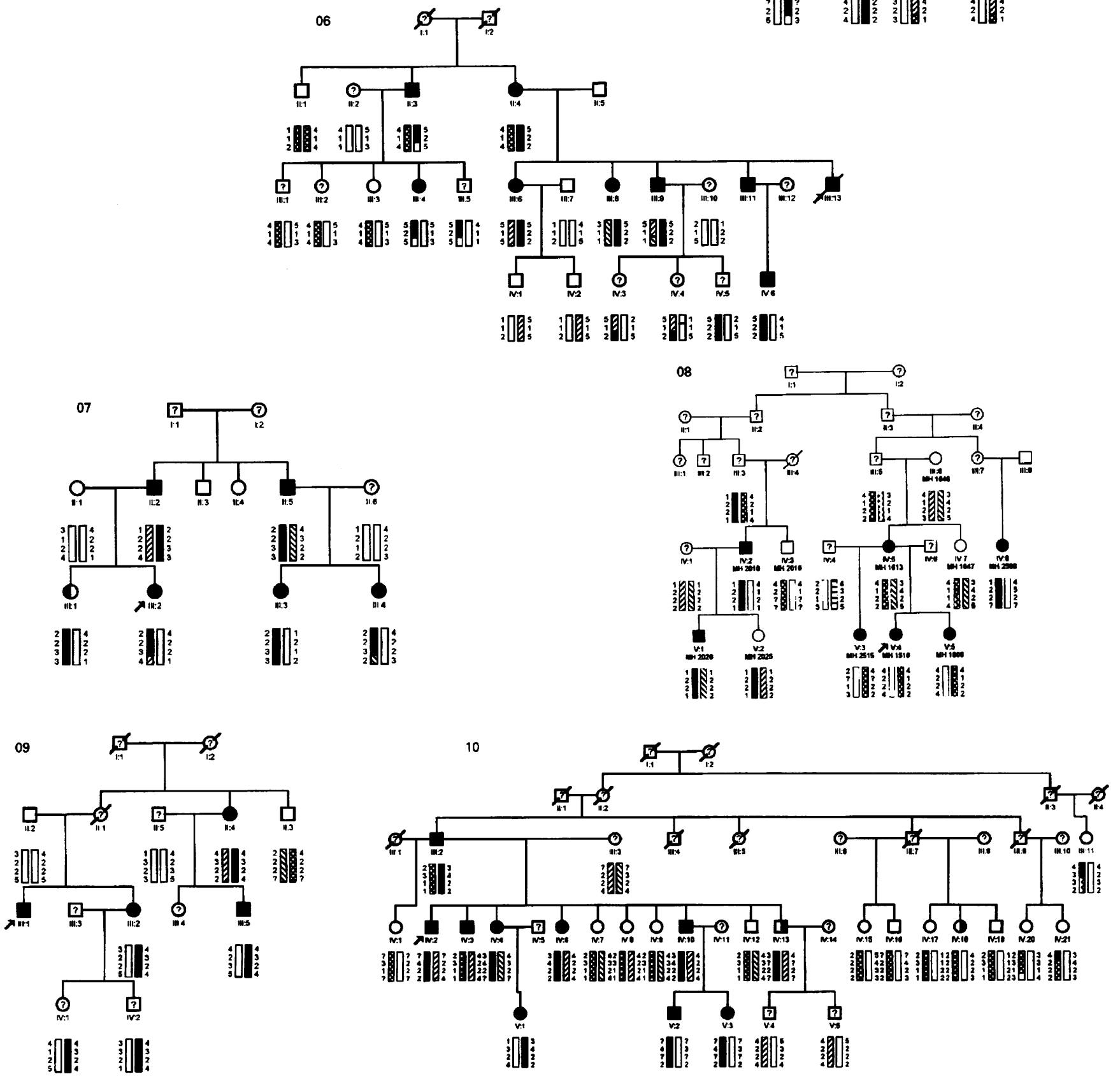

Figure 1 Pedigrees of the 20 families used in the study. Filled symbols are MHS, empty symbols MHN, ? indicates untested, half hatched symbols are MHE. Arrows indicate probands. Family numbers are indicated on the top left hand side of each pedigree. 


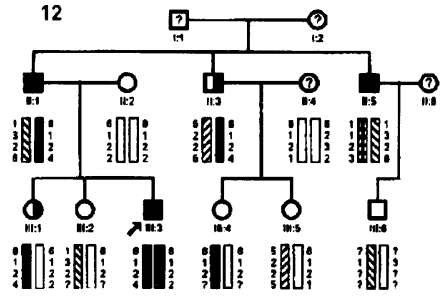

15

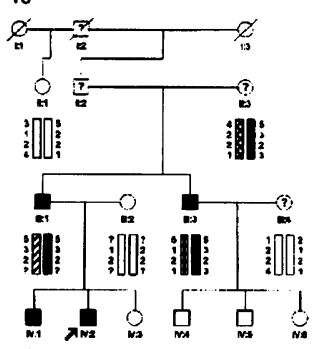

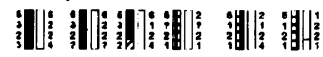

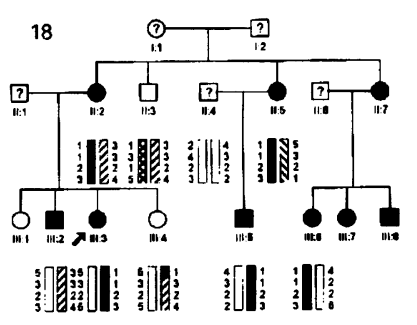

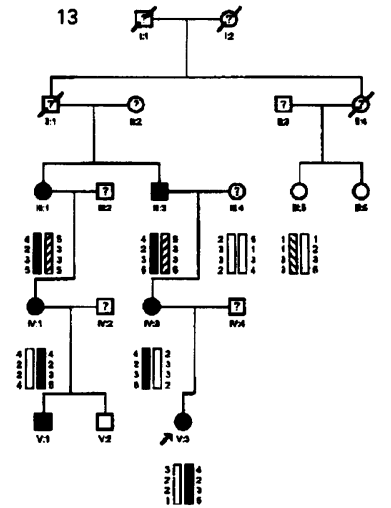
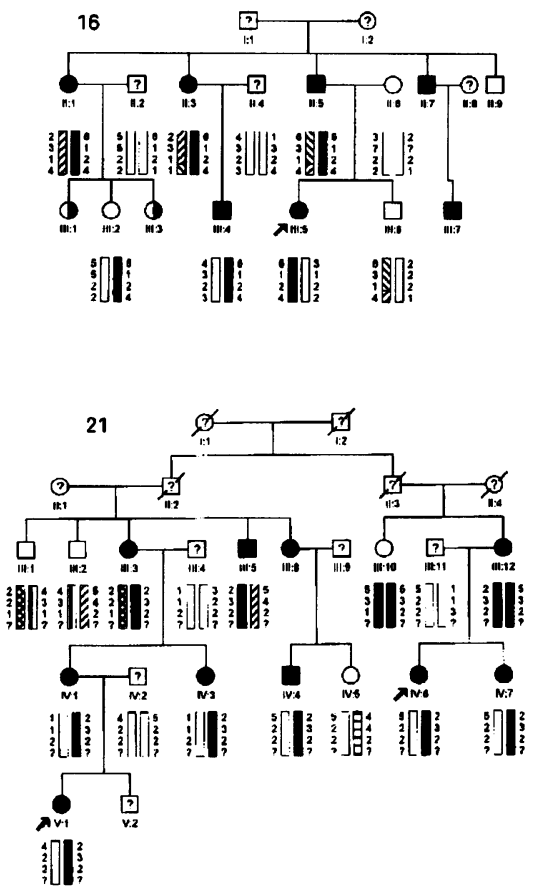

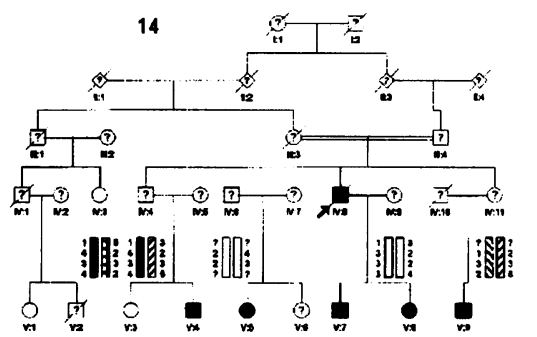

In:
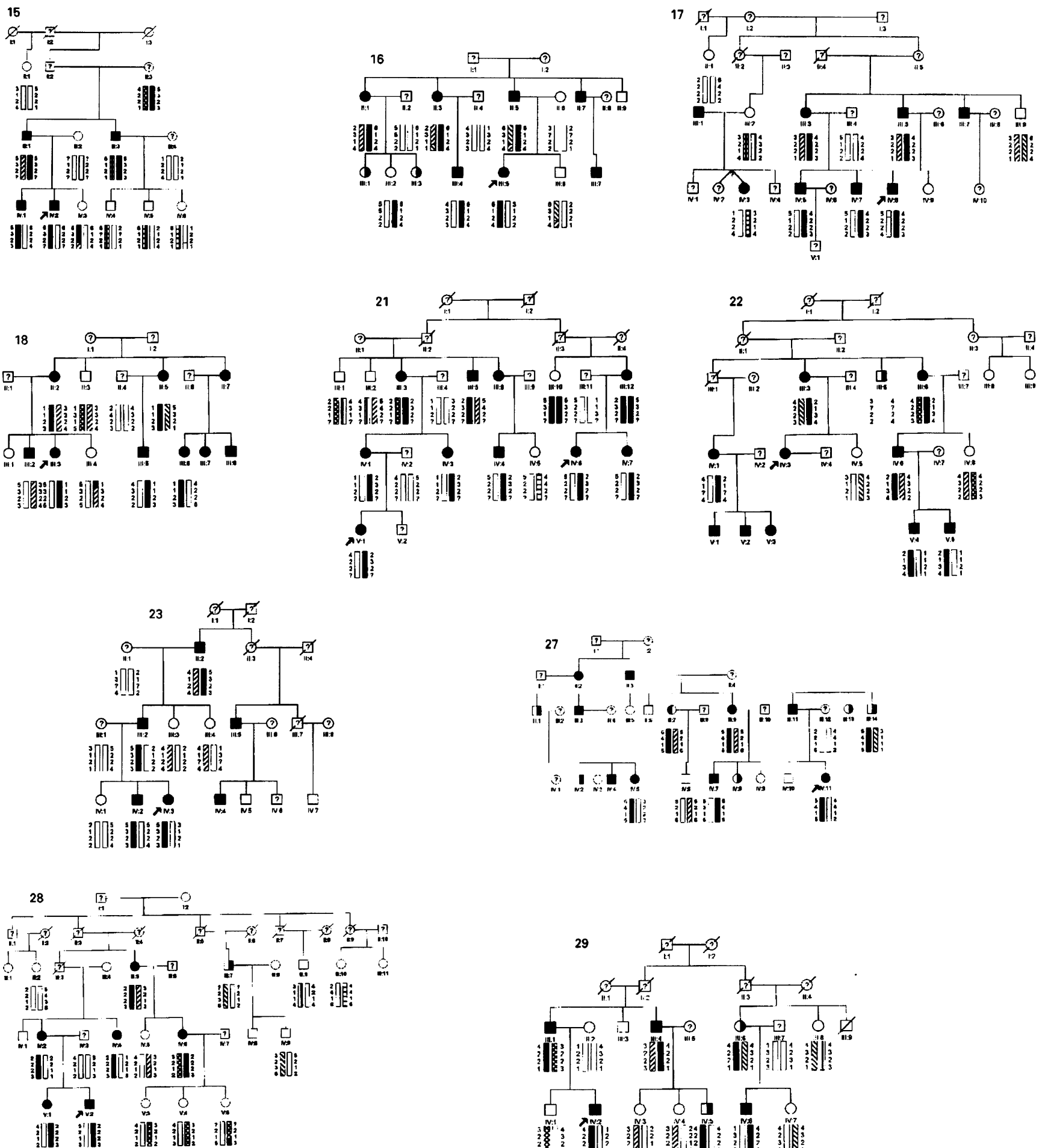
Table 1 Segregation of chromosome 19q13.1-13.2 markers with $M H$ susceptibility

\begin{tabular}{|c|c|c|c|c|c|c|c|}
\hline \multirow[b]{2}{*}{ Family } & \multicolumn{3}{|l|}{ No of subjects } & \multicolumn{4}{|c|}{ Multipoint analysis } \\
\hline & Phenotyped & Genotyped & No of recombinants & Lod score & $\begin{array}{l}\text { HOMOG } \\
\text { probability }\end{array}$ & $\begin{array}{l}\text { Lower } 95 \% \text { support } \\
\text { limit }\end{array}$ & $\begin{array}{l}\text { Upper } 95 \% \text { support } \\
\text { limit }\end{array}$ \\
\hline LMH03 & 21 & 22 & $>3$ & -2.52 & 0.012 & 0.003 & 0.13 \\
\hline LMH05 & 7 & 9 & 1 & 0.88 & 0.97 & 0.88 & 0.99 \\
\hline LMH06 & 14 & 21 & 0 & 2.41 & 0.99 & 0.99 & 1.00 \\
\hline LMH07 & 7 & 8 & 1 & -0.52 & 0.55 & 0.22 & 0.94 \\
\hline LMH08 & 13 & 15 & $\geqslant 1$ & -0.01 & 0.80 & 0.48 & 0.98 \\
\hline $\mathrm{LMH} 10$ & 24 & 27 & 1 & 0.88 & 0.97 & 0.88 & 0.99 \\
\hline LMH12 & 11 & 10 & 2 & -1.01 & 0.28 & 0.08 & 0.83 \\
\hline LMH13 & 9 & 7 & 0 & 1.04 & 0.98 & 0.91 & 1.00 \\
\hline LMH14 & 11 & 10 & 1 & -1.77 & 0.06 & 0.02 & 0.45 \\
\hline LMH15 & 10 & 12 & $\geqslant 2$ & 0.60 & 0.94 & 0.79 & 0.99 \\
\hline LMH16 & 13 & 10 & 1 & -0.24 & 0.69 & 0.35 & 0.97 \\
\hline LMH 17 & 12 & 10 & $0^{\star}$ & 1.12 & 0.98 & 0.92 & 1.00 \\
\hline LMH18 & 12 & 9 & 1 & 0.38 & 0.91 & 0.69 & 0.99 \\
\hline $\mathrm{LMH} 21$ & 11 & 16 & 0 & 4.09 & 1.00 & 0.99 & 1.00 \\
\hline $\mathrm{LMH} 22$ & 10 & 9 & 0 & 1.75 & 0.99 & 0.98 & 1.00 \\
\hline $\mathrm{LMH} 27$ & 21 & 8 & 0 & 1.47 & 0.99 & 0.96 & 1.00 \\
\hline LMH28 & 19 & 16 & 0 & 2.48 & 0.99 & 0.99 & 1.00 \\
\hline LMH29 & 12 & 13 & 0 & 2.61 & 0.99 & 0.99 & 1.00 \\
\hline
\end{tabular}

^Assuming introduction of a second gene associated with $\mathrm{MH}$ in one branch of the pedigree.

30 thermal cycles each of one minute at $94^{\circ} \mathrm{C}$, 30 seconds at $54^{\circ} \mathrm{C}$, one minute at $72^{\circ} \mathrm{C}$; finally there was a 10 minute incubation at $72^{\circ} \mathrm{C}$. For the primers for RYR1, PCRs for flanking markers were performed as for the RYR1 repeat except annealing temperatures were as follows: D19S191 $45^{\circ} \mathrm{C}$, D19S47 $57^{\circ} \mathrm{C}$. The resultant products were analysed by electrophoresis on a $6 \%$ denaturing polyacrylamide gel at $60 \mathrm{~W}$ for three hours. The gel was then fixed, dried, and exposed to fast, blue $x$ ray film (Genetic Research Instrumentation) for 12 to 36 hours. Families uninformative for any of the markers were typed with further closely flanking markers on 19q13 (data not shown).

Two point lod scores were obtained using LINKAGE v 5.04, assuming gene penetrances of 0.98 and 0.98 for the normal and susceptibility alleles respectively, and a disease gene frequency of 1:5000 (these are the figures agreed by the Genetics Section of the European Malignant Hyperthermia Group). Multipoint lod scores and the HOMOG v 3.3 analyses ${ }^{13}$ were performed at the MRC Human Genome Mapping Project resource centre, Cambridge, UK. Multipoint lod scores were generated using LINKAGE with LINKMAP. The disease locus was placed within a fixed map of three markers, D19S191, WUT1.9, and RYR1. The intermarker $\theta$ values used were as follows: D19S191, $\theta=0.021$; WUT 1.9, $\theta=0.002 ; \mathrm{RYR} 1, \theta=0$. These values were calculated on the basis of physical mapping data and assuming $1 \mathrm{Mb}=1 \mathrm{cM}, 1 \mathrm{cM}=\theta$ of 0.01 . As the genetic distances were so small, intermarker values of $\theta$ could not be accurately computed using the data set discussed here.

\section{Results}

The results from 20 families, incorporating 250 phenotyped and 249 genotyped subjects, were analysed. The segregation of the chromosome 19q13.1-13.2 markers with $\mathrm{MH}$ susceptibility is summarised in table 1 , along with the multipoint lod scores and the results of the HOMOG analyses.
In nine of the families, segregation was consistent with linkage of $\mathrm{MH}$ susceptibility to RYR1, whereas in three families there were at least two recombinants, strongly suggestive of MH not being caused by RYR1, although in only one family did the lod score reach -2.0 . It was especially in the remaining families, where segregation was incomplete owing to a single recombinant subject, that we envisaged that the likelihood of linkage to RYR1 generated by the HOMOG analyses would be useful.

\section{Discussion}

Published linkage studies of malignant hyperthermia have been carried out on remarkably few large, well characterised families. This is mainly because of the nature of the phenotyping process, which involves open muscle biopsy carried out at a diagnostic centre often a long distance from the patient's home. These studies have, however, enabled the identification of the MHS1 locus RYR1 and also indicated that there is genetic heterogeneity underlying malignant hyperthermia. Levitt et $a l^{10}$ presented three families where linkage to 19q13.1-q13.2 was excluded, but the results presented in that paper are difficult to evaluate as there are no means to appraise the phenotypes critically (absence of muscle contracture data). A report by Deufel et $a l^{11}$ suggested that two Central European families also showed no linkage between malignant hyperthermia susceptibility and the 19q13.1 region. Similarly, Fagerlund et $a l^{12}$ described recombinants between RYR1 and malignant hyperthermia susceptibility in two out of three Swedish families segregating informatively at the RYR1 locus. The presence of genetic heterogeneity in $\mathrm{MH}$ dictates that great caution be exercised when combining data from several small families. ${ }^{20}$ This could be why the report of linkage to chromosome $17 \mathrm{q}$ by Levitt et $a l^{1}$ has yet to be substantiated..$^{22}$ Confirmation of genetic heterogeneity has been provided by the results of a genomic search that identified a high probability of linkage between $\mathrm{MH}$ susceptibility and chromosome $3 q^{24}$ and a fur- 
ther gene on chromosome $1 \mathrm{q} \cdot{ }^{25} \mathrm{~A}$ further linkage region containing the gene for the $\alpha 2 / \delta$ subunit of the skeletal muscle dihydropyridine calcium channel complex on chromosome $7 \mathrm{q}$ has also been reported. ${ }^{26}$

While most authorities agree that genetic heterogeneity does exist, the proportion of families linked to RYR1 has not been determined. This again is probably the result of the difficulty in obtaining well characterised $\mathrm{MH}$ pedigrees. Such an estimate is important because it would give an indication of the proportion of families in which the diagnosis of $\mathrm{MH}$ could be made using the flanking DNA marker approach of Healy et al. ${ }^{9}$ It would also provide the likelihood of finding a mutation in RYR1 of individual $\mathrm{MH}$ susceptible patients in whose family there were insufficient members to use a linkage approach. In this context it is interesting to note that the RYR1 mutations so far reported have been found in only about $10-15 \%$ of $\mathrm{MH}$ subjects screened. ${ }^{27}$ In addition, a number of families have now been recorded in which the $\mathrm{MH}$ status as determined by the IVCT does not correlate with the RYR1 mutation results. ${ }^{28} 29$

The patient resource of the UK MH Investigation Unit, with more than 3500 people from over 500 families phenotyped by contracture testing, is the largest of its kind in the world. From these families we have selected 20 pedigrees with a structure and size potentially capable of providing informative linkage data. Using the number of subjects showing recombinations between RYR1 and MH susceptibility (table 1) and our current understanding of the molecular genetics of $\mathrm{MH}$, it is possible to place these families into one of three categories. The first category includes the nine pedigrees where there is complete segregation between RYR1 and MH susceptibility, which is wholly consistent with linkage to RYR1 in these families. The second category, consisting of three pedigrees, is that in which there are at least two recombinants between RYR1 and MH susceptibility, suggesting that linkage to the RYR1 is unlikely. The third category consisting of the remaining eight families is where there is one recombinant, making it difficult to assign this pedigree to be linked or not linked to RYR1. Within these three categories the families vary in the size of the lod score, depending on the number of people and how informative the markers were in them.

In order to obtain a more precise estimate of the proportion of families linked to RYR1, we applied the analysis provided by the HOMOG program designed for this purpose. ${ }^{13}$ HOMOG compares two hypotheses, heterogeneity with linkage and homogeneity with linkage to the null hypothesis of no linkage in a pairwise manner, using an Admixture test. This analysis provided quantitative support for the hypothesis that category 1 families are very likely to be linked to RYR1. The HOMOG probability values calculated from the multipoint lod scores were between 0.98 and 1 . The probability values calculated from the two point lod scores were lower, although all were greater than 0.90 . The estimates of the probability of linkage to RYR1 obtained by HOMOG analysis for the second category of families (those with two or more recombinants) varied in two of the three families depending on whether the probability value was based on the multipoint or two point lod score. These estimates were accompanied by wide $95 \%$ confidence limits. For example, for family LMHO3, the confidence interval was from 0.003 to 0.129 , while for family $\mathrm{LMH} 12$ the corresponding range was 0.083 to 0.827 ; both these values relate to the multipoint lod score. Even wider confidence intervals were obtained when the HOMOG probability was derived from the two point lod score. The third family in this category, LMH15, had HOMOG probabilities of 0.91 and 0.94 for the two point and multipoint analyses respectively; these results were not anticipated from either the segregation pattern of the RYR1 markers with $M H$ susceptibility or the lod scores. HOMOG probability values for the third category of families, where there was only one recombinant between RYR1 and MH susceptibility, were even more unhelpful. The estimates again varied according to whether the probability estimate was derived from the multipoint or two point lod score; once more, the confidence intervals were wide. The HOMOG analysis was, therefore, of little help in providing additional evidence as to whether an individual family is linked to RYR1 or what proportion of families with malignant hyperthermia is linked to this region.

Our results do, however, show for the first time that malignant hyperthermia susceptibility is not linked to chromosome $19 \mathrm{q}$ in all British families. The large proportion of families in which we have found a single recombination event is perhaps surprising. One possibility is that the phenotyping of these recombinant subjects is wrong. The IVCT was designed with an inbuilt bias for reasons of clinical safety, so that occasional false positives will occur, but false negatives should not. It would anyway be hard to explain all these single recombinant families merely by invoking an incorrect IVCT result. This raises the question of whether inheritance of a second gene is important in the expression of $\mathrm{MH}$ susceptibility in these families. ${ }^{30}$ Indeed, there is clear evidence of the participation of a second gene in family LMH17. Until this possibility has been further investigated and in the presence of established genetic heterogeneity in $\mathrm{MH}$, it cannot be considered safe to rely on DNA analysis for clinical diagnosis of malignant hyperthermia.

We thank Professor D T Bishop of the ICRF Epidemiology Unit for his helpful advice and comments. JLC is supported by a $\mathrm{PhD}$ student. Research in the authors' laboratory is also supported by the MRC and the Wellcome Trust.

1 Ellis FR, Halsall PJ, Harriman DGF. The work of the Leeds Malignant Hyperpyrexia Investigation Unit, 1971-1984. Anaesthesia 1984;41:809-15.

2 MacLennan DH, Duff C, Zorzato F, et al. Ryanodine receptor gene is a candidate for predisposition to malignant tor gene is a candidate for predisposition

3 McCarthy TV, Healy JMS, Heffron JJA, et al. Localisation of the malignant hyperthermia susceptibility locus to human chromosome 19q12-13.2. Nature 1990;343:562-4. 
4 Stewart AD, Hall JL, Taylor GR, et al. Genetic linkage analysis using microsatellites in human malignant hyperthermia. Human Gene Mapping 11. Cytogenet Cell Genet 1991;58:2025.

5 Ball SP, Dorkins HR, Ellis FR, et al. Genetic linkage analysis of chromosome 19 markers in malignant hyperthermia. $\mathrm{Br}$ f Anaes 1993;70:70-5.

6 Couch FJ, Gillard BF, MacLennan DH, et al. Linkage mapping of malignant hyperthermia to the skeletal muscle ping of malignant hyperthermia to the skeletal muscle ryanodine receptor (RYR1) on chromosome 19. Humat

7 Fujii J, Otsu K, Zorzato F, et al. Identification of a mutation in the porcine ryanodine receptor that is associated with in the porcine ryanodine rece

8 Otsu K, Khanna VK, Archibald AL, MacLennan DH Cosegregation of porcine malignant hyperthermia and a probable causal mutation in the skeletal muscle ryanodine receptor gene in backcross families. Genomics 1991;11:744 50.

9 Healy JMS, Heffron JJA, Lehane M, Bradley DG, Johnson $\mathrm{K}$, McCarthy TV. Diagnosis of susceptibility to malignan hyperthermia with flanking DNA markers. BMF 1991;303: 1225-8.

10 Levitt RC, Nouri N, Jedlicka AE, et al. Evidence for genetic heterogeneity in malignant hyperthermia susceptibility. Genomics 1991;11:543-7.

11 Deufel T, Golla A, Iles D, et al. Evidence for genetic heterogeneity of malignant hyperthermia susceptibility. $A m$ Geneity of malignant hypert.

12 Fagerlund T, Islander G, Ranklev E, et al. Genetic recombination between malignant hyperthermia and calcium release channel in skeletal muscle. Clin Genet 1992;41:270 2.

13 Ott J. Analysis of human genetic linkage. 2nd ed. Baltimore: Johns Hopkins University Press, 1991.

14 European Malignant Hyperpyrexia Group. A protocol fo the investigation of malignant hyperpyrexia $(M H)$ susceptibility. Br f Anaes 1984;56:1267-9.

15 Weber JL, May PE. An abundant class of human DNA polymorphisms which can be typed using the polymerase chain reaction. Am ₹ Hum Genet 1989;44:388-96.

16 Couch FJ, Hogan K, McCarthy TV, Gregg RG. Dinucleotide repeat polymorphism at the RYR1 locus (19q13.1). Nucleic Acids Res 1991;19:5094.

17 Iles DE, Segers B, de Jong P, Alleman J, Wieringa B. Dinucleotide repeat polymorphism at the D19S191 locus. cleotide repeat polymorphism
Nucleic Acids Res 1992;20:1170.

18 Weissenbach J, Gyapay G, Dib C, et al. A second generation linkage map of the human genome. Nature 1992;359:794801 .
19 Sakiki RK, Gelfand DH, Stoffel S, et al. Enzymatic amplification of beta-globin sequences and restriction site analysis for diagnosis of sickle cell anaemia. Science 1988;239:48791.

20 Johnson KJ. Malignant hyperthermia hots up! Hum Mol Genet 1993;2:7.

21 Levitt RC, Olckers A, Meyers S, et al. Evidence for the localisation of a malignant hyperthermia susceptibility locus (MHS2) to human chromosome 17q. Genomics 1992;14:562-6.

22 Sudbrak R, Golla A, Powers $\mathrm{P}$, et al. Exclusion of malignan hyperthermia susceptibility (MHS) from a putative MHS2 locus on chromosome $17 \mathrm{q}$ and of the alpha 1 , beta 1 and gamma subunits of the dihydropyridine receptor calcium channel as candidates for the molecular defect. Hum Mol Genet 1993;2:857-62.

23 Iles DE, Segers B, Sengers RC, et al. Genetic mapping of the $\beta 1$ and $\gamma$ subunits of the human skeletal muscle L-type voltage-dependent calcium channel on chromosome 17q and exclusion as candidate genes for malignant hyperthermia susceptibility. Hum Mol Genet 1993;2:863-8.

24 Sudbrak R, Procaccio V, Klautsnitzer M, et al. Mapping of a further malignant hyperthermia susceptibility locus to chromosome 3q13.1. Am $\mathcal{F}$ Hum Genet 1995;56:684-91

25 Iles DE, Lehmann-Horn F, Scherer SW, et al. Localization of the gene encoding the $\alpha 2 / \delta$ - subunits of the L-type voltage-dependent calcium channel to chromosome $7 \mathrm{q}$ and analysis of the segregation of flanking markers in malignant hyperthermia susceptible families. Hum Mol Genet 1994;3: 969-75.

26 Robinson RL, Monnier N, Wolz W, et al. A genome wide search for susceptibility loci in three European malignan hyperthermia pedigrees. Hum Mol Genet 1997;6:953-61.

27 Phillips MS, Fujii J, Khanna VK, et al. The structura organisation of the human skeletal muscle ryanodine receptor (RYR1) gene. Genomics 1996;34:24-41.

28 Deufel T, Sudbrak R, Feist Y, et al. Discordance, in a malignant hyperthermia pedigree, between in vitro contracturetest phenotypes and haplotypes for the MHS1 region on chromosome 19q12-13.2, comprising the C1840T transition in the RYR1 gene. Am $\mathcal{F}$ Hum Genet 1995;56:1334-42.

29 Adeokun AM, West SP, Ellis FR, et al. The G1021A substitution in the RYR1 gene does not cosegregate with malignant hyperthermia susceptibility. Am 7 Hum Genet 1997;60:833-41.

30 Hopkins PM, Halsall PJ, Ellis FR. Diagnosing malignant hyperthermia susceptibility. Anaesthesia 1994;49:373-5. 